\title{
Aplikasi Mikrokontroler Atmega8535 Pada Robot Cerdas Pengangkut Tempat Sampah (Box) Menggunakan Sensor Warna Tcs3200
}

\author{
Suhada $^{1}$, Hasdari Helmi ${ }^{2}$ \\ ${ }^{1}$ Prodi Komputerisasi Akuntansi, AMIK Tunas Bangsa, Pematangsiantar, Indonesia \\ ${ }^{2}$ Fakultas Teknik, Teknik Elektro, Universitas Sumatera Utara, Medan, Indonesia \\ Email: ${ }^{1}$ suhada.atb@gmail.com, ${ }^{2 *}$ helmitom@yahoo.co.id
}

\begin{abstract}
Abstrak
Robot merupakan sebuah alat yang pada dasarnya berfungsi untuk mempermudah pekerjaan manusia. Robot pengangkut tempat sampah dapat dimanfaatkan oleh penggunanya yaitu masyarakat untuk dapat membantu memberikan kemudahan pada kebersihan lingkungan. Program yang digunakan pada robot menggunakan bahasa $\mathrm{C}$ yang di proses pada aplikasi CodeVision AVR. Langkah-langkah penyelesaian aplikasi dalam penelitian ini adalah merancang program, membuat program, melakukan pengujian terhadap robot, perbaikan dan yang terakhir proses penyempurnaan program. Program dapat diimplementasikan dengan syarat adanya hardware yang akan menjadi output dari hasil penelitian keseluruhan. Program dalam Aplikasi Mikrokontroler ATMega8535 Pada Robot Cerdas Pengangkut (Box) Tempat Sampah ini dapat dijadikan pedoman bagi para pengguna teknologi untuk menambah ilmu pengetahuan dan turut melanjutkan inovasi penciptaan teknologi baru yang bermanfaat.
\end{abstract}

Kata Kunci: Robot, Tempat sampah, Program, Sensor

\begin{abstract}
The robot is a tool that is basically serves to make something easy in human's work. Trash hauler robot can be utilized by people to assist in providing ease for the cleanlines of the environment. The robot uses program language $\mathrm{C}$ which is processed in application of CodeVision AVR. Completion of the steps in the application of this research is to design a program, create a program, do a test of the robot, refinement of program, and the last is the process of program improvement. The Program could be implemented by requiring there is hardware that will be output of the whole research result. The Program is inside of Microcontroller Application ATMega8535 on this intellegent robot of hauler (Box) Trash can be used as a guide for users of technology to increase knowledge and continue the innovation of the useful new technology creation.
\end{abstract}

Keywords: Robot, Trash, Program, Sensor

\section{PENDAHULUAN}

Di lingkungan masyarakat masih banyak kebiasaan yang kurang memenuhi faktor kebersihan. Yaitu ketika dinas petugas kebersihan harus mengangkut tempat sampah secara manual dari tempat sampah yang telah disediakan di depan pekarangan warga. Tempat sampah ini dibedakan menjadi dua jenis sampah yaitu sampah basah dan sampah kering. Sampah adalah zat kimia, energi atau makhluk hidup yang tidak mempunyai nilai guna dan cenderung merusak [1]. Kedua sampah ini harus dipindahkan ke tempat pembuangan akhir sesuai dengan jenisnya.

Pembuatan aplikasi untuk menjalankan robot pengangkut tempat sampah menggunakan sensor warna TCS 3200 sebagai pendeteksi warna tempat sampah dan sensor cahaya sebagai pendeteksi jalur hitam pada jalur lintasan yang disebut juga dengan Line Follower dimana robot akan berjalan untuk mengangkut tempat sampah sesuai dengan jalur yang sudah ditentukan. Hasil pendeteksian sensor warna TCS 3200 akan ditampilkan pada LCD (Liquid Cristal Display). Servo berperan dalam mengangkat tempat sampah, servor ini dipasang di lengan dan griper robot. Servo ini bekerja berdasarkan lebar pulsa yang diberikan oleh kontrol servo,".. pemberian PWM akan membuat motor servo begerak pada posisi tertentu dan kemudian berhenti (kontrol posisi) [4].

Adapun identifikasi masalah yang akan di selesaikan adalah sebagai berikut:

a. Bagaimana program dibuat agar robot dapat berjalan dan mengangkut tempat sampah (box) yang telah diberi warna merah dan biru?

b. Bagaimana sistem dapat mendeteksi jalur perjalanan robot berdasarkan sensor?

c. Bagaimana cara memahami struktur program, serta bagaimana mengaplikasikan program tersebut?

d. Bagaimana hubungan program dengan pin-pin yang terdapat pada mikrokontroler?

\section{METODE PENELITIAN}

\subsection{Perancangan Diagram Blok Sistem}

Diagram blok memiliki peran yang sangat penting. Adapun diagram blok sistem ini adalah sebagai berikut: 


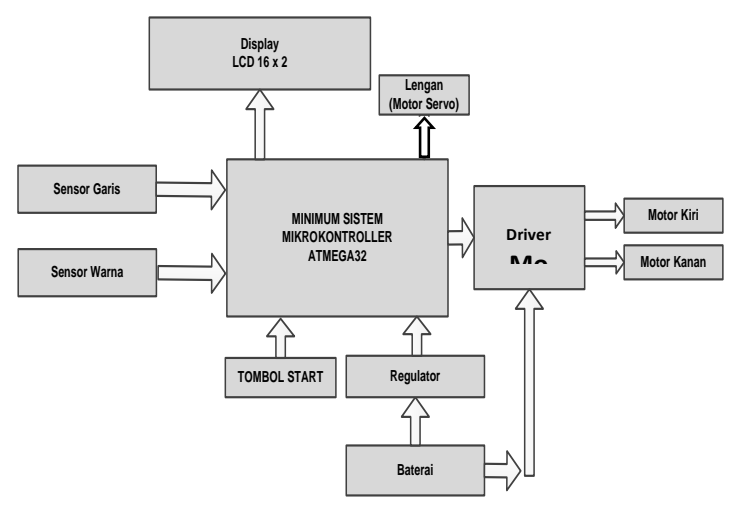

Gambar 1. Diagram Blok Sistem Robot

Jika Power dihidupkan dengan menggunakan catudaya, maka semua kontrol pada mikrokontroler akan bekerja. Ketika sensor garis membaca garis yang ada di lantai berwarna putih, maka sensor garis akan mengirim nilai yang akan di proses di Mikrokontroler ATMega8535. Jika nilai sensor garis tengah bernilai tinggi, maka robot akan berjalan maju kedepan, begitu juga jika sensor garis kanan bernilai tinggi, robot akan berbelok ke kanan. Jika terdapat persimpangan (nilai sensor tengah tinggi, nilai sensor kanan tinggi dan nilai sensor kiri tinggi) maka robot akan mendominasi untuk berbelok ke kanan (right trace). Nilai yang di proses melalui Mikrokontroler akan di tampilkan pada layar LCD. Ketika sensor warna mendeteksi adanya warna pada tempat sampah, maka sensor warna juga akan mengirim nilai yang akan di proses di Mikrokontroler ATMega8535.

Dengan menggunakan sensor Warna TCS3200, proses pendeteksian warna berupa adanya flash sebanyak dua kali dengan tujuan agar pendeteksian warna lebih akurat. Lengan robot akan bergerak ketika akan mengangkut objek yang diikuti dengan pendeteksian warna terlebih dahulu. Setelah warna terdeteksi maka greeper (capit) pada robot akan mengangkut objek tersebut.

\subsection{Perancangan Rangkaian Robot}

Perancangan rangkaian robot diperlukan untuk merancang layout pada papan PCB sekaligus untuk mempermudah dalam melakukan troubleshoot rangkaian apabilatimbul permasalahan dari rangkaian yang telah dibuat. Dibawah ini adalah gambar rangkaian robot pengangkut tempat sampah secara keseluruhan.

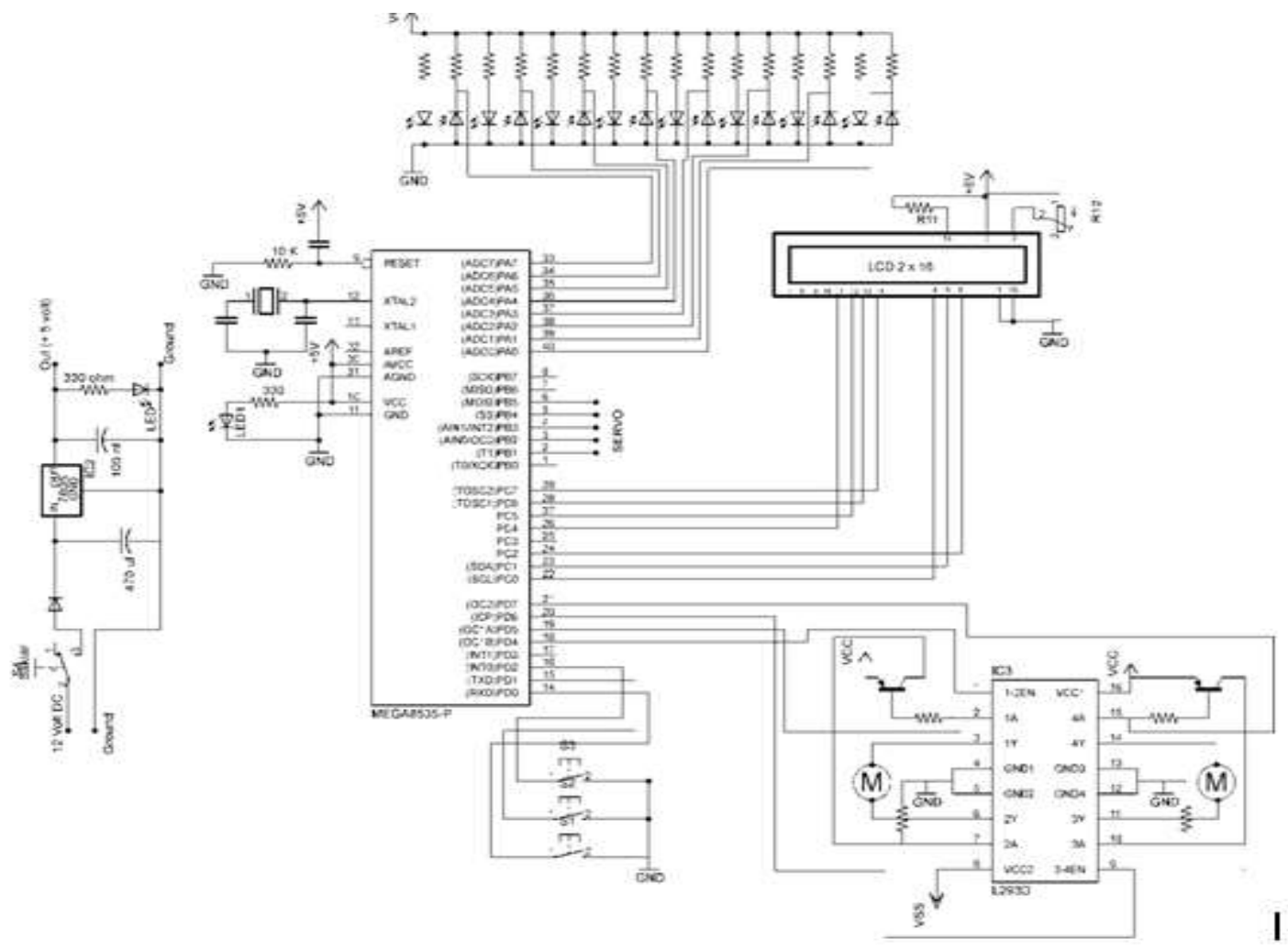

Gambar 2. Rancangan Rangkaian Robot Pengangkut Tempat Sampah 
Adapun penjelasan cara kerja dari masing masing alat yang digunakan pada rangkaian robot pengangkut Tempat sampah (box).

a. Mikrokontroller ATMEGA 8535 adalah sebagai pengendali sistem kerja rangkaian robot. Dimulai dari mengolah data yang diberikan sensor sampai mengirimkan perintah kerangkaian lain sehingga robot dapat bekerja sesuai dengan yang diinginkan.

b. Sensor garis sebagai pembaca jalur hitam agar robot dapat berjalan sesuai dengan jalur yang telah ditentukan.

c. Sensor Warna TCS2300 sebagai pendeteksi warna dari tempat sampah sehingga robot dapat menempatkan jenis sampah sesuai dengan tempat sampah nya.

d. L293D sebagai driver Motor DC untuk menggerakkan roda-roda pada robot agar dapat berjalan dengan ketentuan yang telah dibuat. IC L293D merupakan rangkaian H-Bridge yang dirancang untuk memberikan arus dua arah hingga 1,2 A dengan tegangan antara 4,5 V hingga $36 \mathrm{~V}$ kepada motor DC. IC ini disebut juga sebagi IC penggerak motor. "IC penggerak motor adalah IC tidak terprogram yang memiliki fungsi khusus sebagai penggerak (driver)dari suatu motor DC berspesifikasi tertentu [2].

e. Display LCD sebagai penampil hasil pendeteksian sensor warna TCS3200 serta untuk tampilan kondisi kalibrasi sensor garis dan sensor warna.

f. Power Supply sebagai sumber tegangan yang dipelukan rangkaian, dengan dilengkapi IC 7805 sebagai penstabil tegangan yang keluar agar tetap 5 volt.

\subsection{Perancangan Flowchart Robot Pendeteksi Sampah}

Perancangan flow chart robot pengangkut tempat sampah merupakan gambaran dari system kerja yang akan berjalan pada robot pengangkut tempat sampah serta mempermudah dalam perancangan perangkat lunak.

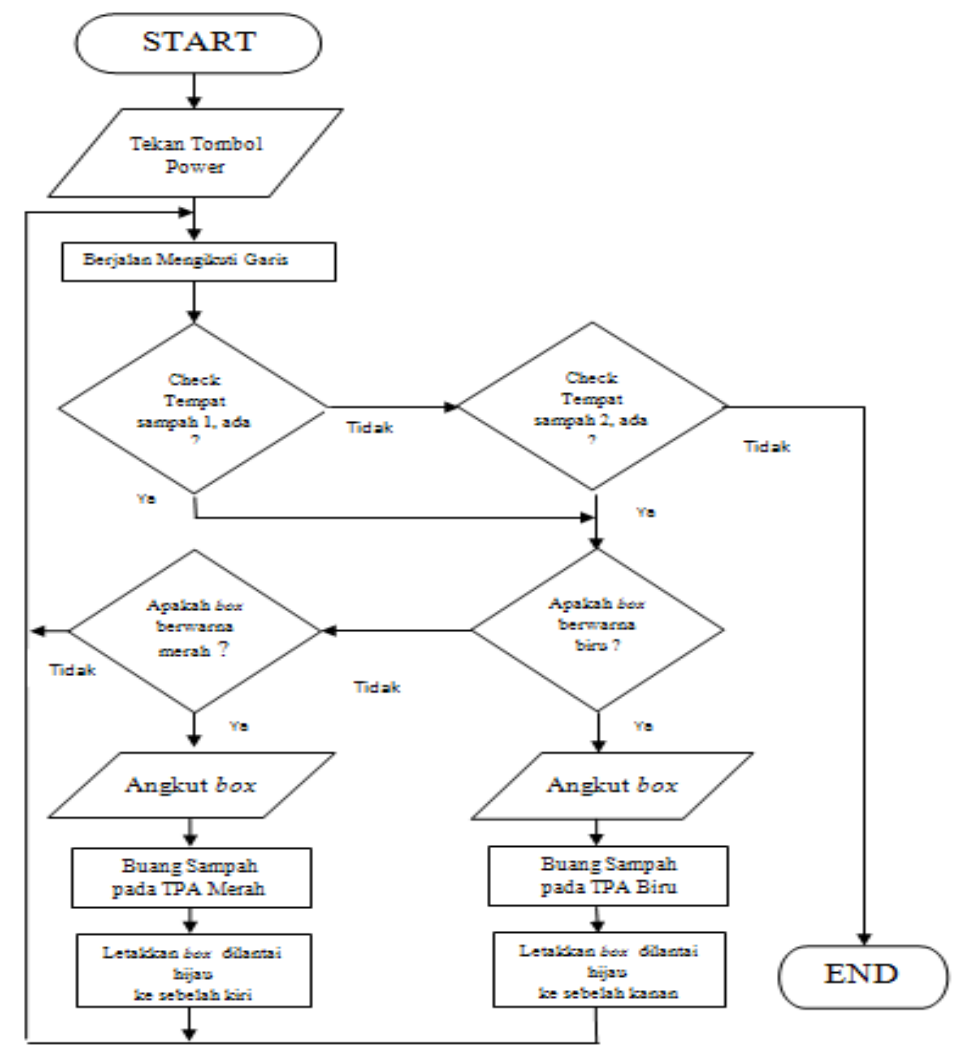

Gambar 3. Flowchart Robot Pengangkut Tempat Sampah

Flowchart sangat menentukan alur dari jalan sistem kerja dari robot karena program dibuat berdasarkan flowchart yang telah dirancang.

\subsection{Perancangan Perangkat Lunak}

Perancangan perangkat lunak menggunakan bahasa pemrograman C. Bahasa $\mathrm{C}$ merupakan bahasa pemrograman terstruktur, strukturnya menggunakan fungsi-fungsi sebagai program-program bagian (subroutine). Bahasa $\mathrm{C}$ juga merupakan compiler, karena bahasa $\mathrm{C}$ bersifat compiler, maka akan menghasilkan executable program yang banyak dibutuhkan oleh program-program komersial [3].

\subsection{Ilustrasi Robot Pengangkut Tempat Sampah}

Ilustrasi sistem kerja robot pengangkut tempat sampah menunjukkan sistem kerja keseluruhan robot. Gambar 4 menunjukkan ilutrasi dari sistem kerja robot pengangkut tempat sampah. 


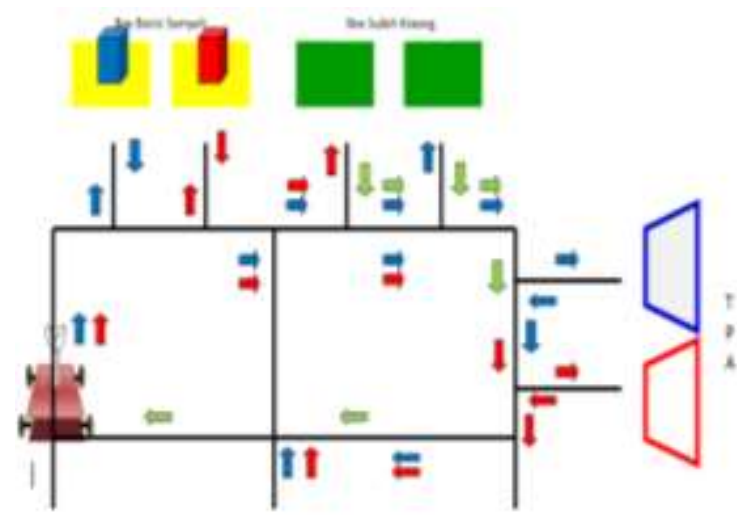

Gambar 4. Ilustrasi Sistem Kerja Robot Pengangkut Tempat Sampah

Penjelasan dari gambar 4 sebagai berikut:

a. Panah berwarna merah menunjukkan alur jalur robot membawa tempat sampah berwarna merah.

b. Panah berwarna biru menunjukan alur jalur robot membawa tempat sampah berwarna biru.

c. Panah berwarna hijau menunjukkan alur jalur robot kembali ke garis start.

Disini robot akan berhenti jika tidak terdapat tempat sampah pada lantai berwarna kuning, karena lantai tersebut merupakan tempat sampah yang telah terisi sampah dan harus dibawa ketempat pembuangan sampah akhir (TPA) yang sesuai dengan warna tempat sampah yang dibawa

\section{ANALISA DAN PEMBAHASAN}

\subsection{Hasil}

Hasil dari pada aplikasi mikrokontroler ATMEGA 8535 pada robot cerdas pengangkut tempat sampah (box) menggunakan sensor wana TCS 2300 berupa robot pengangkut tempat sampah yang dapat diimplementasikan ke lingungan masyarakat untuk membantu permasalahan masyarakat terhadap sampah. Implementasi dan Pengujian sistem dilakukan untuk membuktikan apakah rangkaian yang sudah dibuat bekerja sesuai dengan yang direncanakan. Dalam setiap pengujian dilakukan dengan pengukuran yang nantinya akan digunakan untuk menganalisa hardware dan software pendukungnya.

\subsubsection{Hasil dari Perancangan Robot Pengangkut Tempat Sampah (Box)}

Seperti terlihat pada gambar di bawah ini adalah hasil pada perancangan robot pengangkut tempat sampah (box) dimana masing masing komponen telah terpasang dengan baik dan siap untuk dijalankan

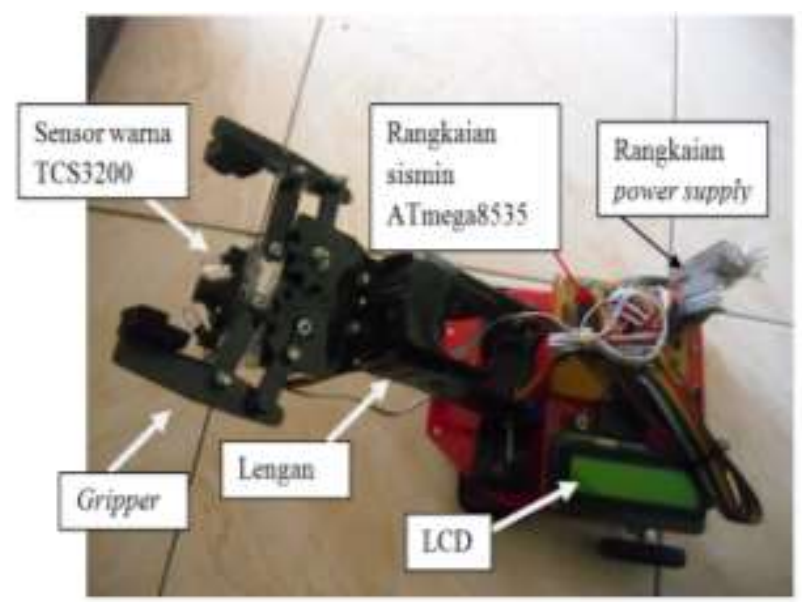

Gambar 5. Robot Pengangkut Tempat Sampah (Box)

Keseluruhan rangkaian ini akan di uji coba berdasarkan program yang tealh dibuat untuk mengendalikan kinerja robot.

\subsubsection{Hasil dari Perancangan Robot Pengangkut Tempat Sampah (Box)}

Gambar 6 berikut merupakan hasil dari perancangan sensor garis, sensor ini akan memberi input kepada mikrokontroler untuk menentukan arah jalan robot sesuai dengan program yang sebelumnya telah dibuat. 


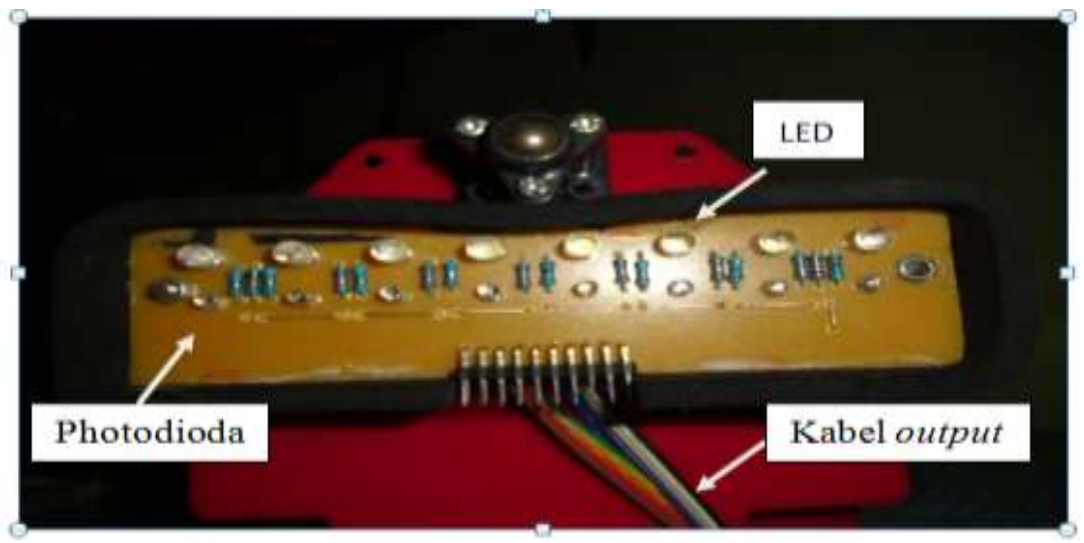

Gambar 6. Sensor Garis

Gambar 7 menujukkan proses kalibari dari sensor garis untuk menguji sensifitas sensor terhadap garis hitam.

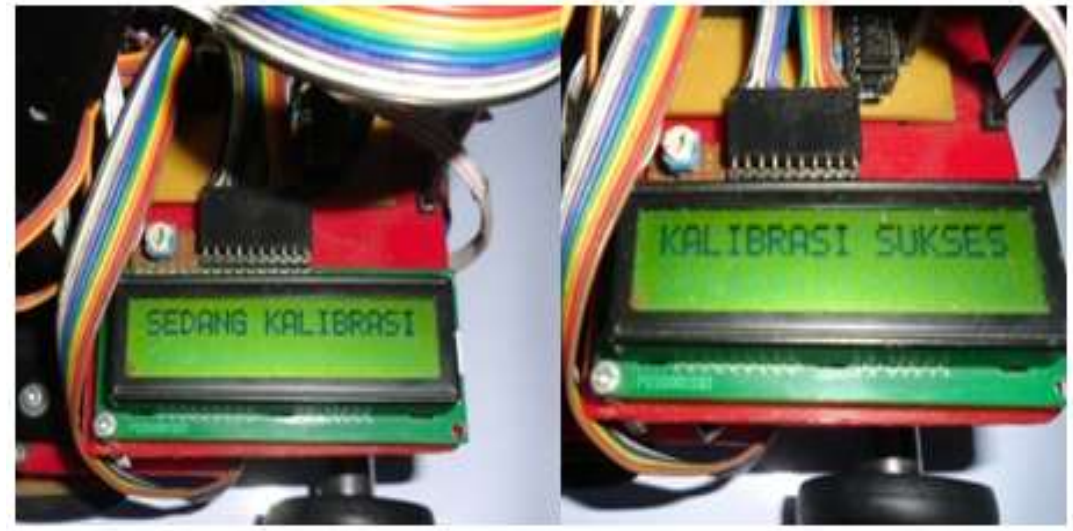

Gambar 7. Pengujian Sensor Garis

Keakuratan sensor garis dalam mendeteksi jalur sangat ditetukan oleh program kalibrasi. Program ini akan menyesuaikan hasil pembacaan awal pada saat kalibrasi setiap sensor dan hasilnya akan dijadikan acuan pada saat sensor melakukan pembacaan jalur.

\subsubsection{Hasil Pengujian Sensor Warna}

Gambar 8 menunjukan hasil pengujian sensor warna berdasarkan program yang telah dibuat dalam mendeteksi warna. Sensor ini memberikan input ke mikrokontroller untuk proses kerja robot dalam menetukan warna teampat sampah yang akan diangkut.

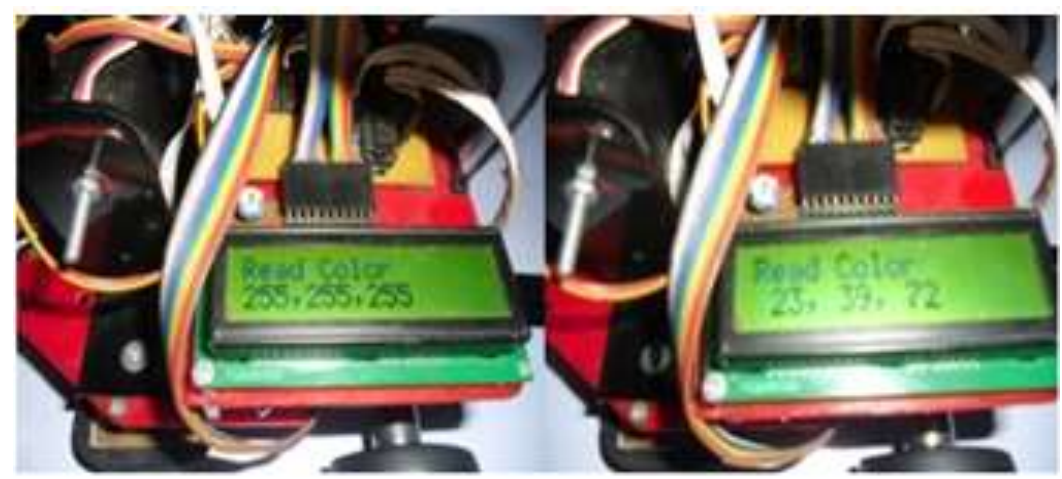

Gambar 8. Pengujian Sensor Warna

Pengujian ini bertujuan unuk menguji sensitivitas sensor warna dalam mendeteksi warna tempat sampah (box). Dengan program kalibrasi sensor warna, kinerja sensor dapat ditingkatkan, karena setiap kalibrasi sensor akan menyimpan hasil pembacaan kalibrasi dan digunakan sebagai acuan pada saat sensor warna bekerja mendeteksi tempat sampah (box) dan program akan memunculkan hasil pembacaan dari sensor warna pada layar LCD seperti yang terlihat pada gambar 8 . 


\section{KESIMPULAN}

Berdasarkan hasil pengujian yang dilakukan dan pembahasan dalam tugas akhir ini dapat diambil beberapa kesimpulan sebagai berikut :

a. Telah dibangun sebuah Aplikasi Mikrokontroler AtMega8535 Pada Robot Pengangkut Tempat Sampah (Box) Menggunakan Sensor Warna TCS3200.

b. Program robot pengangkut tempat sampah (box) dibuat dengan cara membuat flowchart serta algoritmanya terlebih dahulu serta dukungan CodeWizard AVR yang memudahkan penulisan program.

c. Sistem dapat mendeteksi jalur perjalanan robot berdasarkan sensor dengan input nilai analog menjadi nilai digital yang diproses pada mikrokontroler.

d. Untuk mengetahui hubungan antara pin-pin pada mikrokontroler dengan program dapat dilihat pada listing program yang diatur melalui CodeWizard AVR kemudian dilanjutkan dengan percobaan.

Struktur program dapat dipahami dengan rancangan algoritma dan flowchart. Program dapat diaplikasikan apabila terdapat hardware yang menjadi output dari rancangan program

\section{REFERENCES}

[1] Tika Rysma. 2011. Pengelolaan dan pemamfaatan sampah.[Online] Tersedia: http://www.kppm.compd9165.com/index.php/artikel/88pengelolaan-dan-pemanfaatan-sampah [31 Maret 2013].

[2] Suyadhi, T. D. S. 2010. Buku Pintar Robotika : Bagaimana Merancang dan Membuat Robot Sendiri. Yogyakarta : Andi Yogyakarta.

[3] Hartono, Jogiyanto.1992. Konsep Dasar Pemrograman Bahasa C. Yogyakarta : Andi Yogyakarta.

[4] Budiharto, W. 2010. Robotika Teori + Implementasi. Yogyakarta : Andi Yogyakarta 